\begin{tabular}{|c|c|}
\hline 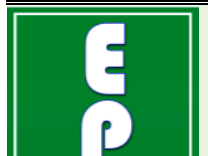 & $\begin{array}{c}\text { International Journal of Current Research } \\
\text { and Academic Review }\end{array}$ \\
\hline $\begin{array}{l}\text { EXCELLENT } \\
\text { PUBLLSHERS }\end{array}$ & $\begin{array}{c}\text { ISSN: 2347-3215 (Online) Volume } 6 \text { Number } 4 \text { (April-2018) } \\
\text { Journal homepage: http://www.ijcrar.com }\end{array}$ \\
\hline
\end{tabular}

doi: https://doi.org/10.20546/ijcrar.2018.604.006

\title{
The Role of Women in Enset Markt Chain the Cause of Dawuro Zone, Southern Nations Nationalities and Peoples Regional State, Ethiopia
}

\author{
Alemayehu Asfaw Amamo* \\ Department of Agribusiness and Value Chain Management, Wolaita Sodo University, P.O.Box 138, Wolaita, Ethiopia \\ *Corresponding author
}

\section{Abstract}

Women play great role in Enset processing to become as edible food item and marketable commodity in Dawuro zone. During Enset processing and supplying to market, women and girls face tedious challenges with related to its value addition and supplying to market through its channel. Chain actor women role was not given emphasis in the area. To these end 201 sample Enset processers, 150 from male headed 51 from female headed household from 24 kebel, 13 local collectors 21 local traders and 6 wholesalers from 3 woreda different level traders identified and selected for current research as sample. Based on the finding of the current research, Enset processing and marketing main activities hold on the shoulder of female than male in the community. Therefore, the Vale addition of kocho, bulla and fiber through processing pseudo stem and corm of enset plant by women was affected at $1 \%$ and $5 \%$ level, positively significant and chopping pseudo stem, kocho, bulla and fiber processing and transporting to marketing area significant at $1 \%$ level in number of femal existence in the family. While, the role of women and girls affected by working culture of the community and poor technology or local equipment, utilization for Enset processing. It may be highly recommended that female capacity building through technology and replacing local processing equipment by technologically improved instrument, awareness creation intervention by government and any responsible body is important solution to reduce women and girls work load in the area.
\end{abstract}

\section{Article Info}

Accepted: 07 March 2017

Available Online: 20 April 2018

\section{Keywords}

Enset,

Processing,

Kocho,

Bulla,

Fiber,

Pseudo stem and corm

\section{Introduction}

Women play great role in Enset processing to become as edible food item in Dawuro zone, because Enset is number one important staple food plants in southern, south eastern and south western Ethiopia. Dawuro zone is one of the zone in which the largest share of the total population depends on Enset plant for their food for the level of consumption in household and for marketing. Enset plant grown in all of the zone at different agro-ecology and the large share is located in high and middle altitude of Tocha, Essara, and Mareka woreda and the fewer shares located in low altitude (kola). Enset plant in the zone considered as an indication of individual household's source of wealth and main source of food that secure an individual farmer household family in food self-sufficiency. If an individual farm household has a potential Enset plant (productive and well managed) by using indigenous knowledge, it grants the household income be secured rather expending for food crop purchase. The community in the zone assures that, an individual's specially farmer 
house hold who has a sufficient Enset plant or at least 0.25 hectare and above holder, is food secured household at family level and if the household head holds two and above cattle including the above introduced level of Enset plant, men shined as food secured at household level and economically strong in the community and even has full right to get couples to be married.

Enset processing activities has clear demarcations between male and female for the long period of time with related to pseudo stem processing, storage of processed kocho and bulla and marketing activities has a clear demarcation between man and women in the community and it was female and grails activities.

The work load in the area performed by women groups such as farm management (duping animal dug and west materials between plants) processing pseudo stem, storage, transporting and marketing activities handled by women groups and it is culturally taboo for male group to process kocho and bulla, store, and transport to market place and selling the Enset produce, therefore, it creates miserable conditions for women in participation and achievement of education and other public and political issues. In addition to that women use very poor and manual tools to Enset processing and transporting, which consume much working time and face them tedious work load, that affect their efficiency and success in the community with compared to man. Resource owning and decision making power varies between man and women in the society and it inclines toward to man in male headed households and it creates biased resource shear and own right between them. While, in female headed household the reverse is true.

The main problem in Enset producer household is the inability to produce at a commercial scale and the loss of its product during processing, the improper storage of the final produce before consumption and lack of knowledge about nutrition. Even though there is enough food, the people are not accustomed to vary their meal to fulfill the nit nutritional requirement. To perform well and to obtain sufficient processed food row material from Enset plant, it is mandatory that improving its production and processing activities by supporting women in Enset processing technology is very important.

More than 20 percent population of the country, concentrated in the highlands of southern and south eastern Ethiopia, depend upon Enset for human food, fiber, animal forage, construction materials, medicines, means of earning cash income and insurance against hunger. Dawuro zone is one of south western part of the regime which has high Enset plant accommodated area and women perform all of Enset processing activities by using traditional instruments to fulfill Enset producer family house consumption food item as well as marketable surplus requirements at household level.

To reduce women work load and to improve their performance in the area Kocho and bulla processing equipment new design from manual to mechanical is very crucial to upgrade the traditional processing system towards to modern style and it might turn the value added "kocho and bulla" product for domestic as well as export market. But all processing activates lay on the shoulder of women with backward technology and it needs serious intervention by responsible body. Therefore, in Dawuro zone women facing challenges with related to work load was yet not known in the area and the role of female in Enset processing, marketing and income generating capacity was not studied.

\section{Statement of the problem}

In Dawuro zone Enset plant play main role in income generating potential for female groups than male and in its production, processing and marketing channel the role of female in the community considered as simple productive work as usual and the value of women activates is not scientifically investigated so far. Enset plant size is big and changing the pseudo stem and its corm to edible food item, consumes much energy and time of female. During Enset processing period women and grilles play significant role, but their activities was not given emphasis in the area. Market channel of the area was not assessed and the role of actors in the chain is not identified scientifically. Therefore, the current study was addressed to fill the Knowledge gap of women role in Enset pseudo stem processing to 'kocho and bulla', management, and marketing potential as compared to mane in the area. Of course what factors affect the Enset value chain and market chain, who acts what or chain actor's role and the intervention mechanism, needed in the area to sustain the value addition of Enset produce and its market channel analysis have been addressed to fill the gap in current study.

\section{General objective}

The general objective of the study was to analyze the significant role playing capacity of women in Enset value chain 


\section{Specific objectives}

To assess the role of women in Enset production, processing and marketing value chain

To identify the market channel of Enset produces (kocho and bulla) in Dawuro zone

\section{Research questions}

What role do women play in processing pseudo stem and corm changing to' kocho and bulla' from Enset plant?

What main activities do women perform in Enset, processing and marketing chain? Who holds the large share of workload and responsibilities?

Is there any intervention by responsible body to reduce work load from women?

\section{Scope and limitation of the study}

The scope of current study based on role of women in Enset producer household of Tocha, Mareka and Esara woreda selected farmers only in the Zone and it can creates farther information foundation for farther analysis for interested scholars. It gives clearly emphasize on how women and grails can increase their economic value or household income through enset processing. The study finding may help for all interested governmental, non-governmental organizations and individual stockholders as information the role of women and girls in Enset processing techniques in the area and its value addition to benefit the producers, traders and consumers. Market channel analysis of the "kocho and bulla" in the study helps producers, local traders, distributers and final consumers as information source by identifying the destination market, because there was no scientific studied conducted in the area yet. Its limitation is related to budget constraints and time limitation, only 30 potentially Enset producing kebeles 200 farmers household's women and 40 different type of traders only included in the study and it does not cover all of the zone farmers. Therefore, it needs important attention on women and girls contribution on enset value addition and facing work load of women in current study.

\section{Significance of the study}

In the study area Enset plant generates income for female group by large and also it boosts to supply household food self-sustain in the community. The economic value of Enset plant for female group is too high as compared to male and value addition practice such as processing pseudo stem and corm take place by female group. Its Value addition and actor's role was yet not identified clearly, it may affect the role of gender in detail. Therefore, Current study can help as source of information for conducting farther scientific research and can encourage the actors in the channel by supplying sufficient information about women role in Enset value and supply chain in the area.

\section{Materials and Methods}

\section{Description of the study area}

\section{Dawuro zone}

Dawuro lies in between $6036^{\prime}$ to $7021^{\prime}$ north latitudes and $36068^{\prime}$ to $37052^{\prime}$ east longitudes. The Gojeb and Omo rivers circumscribe and demarcate Dawuro from northwest to southwest in a clockwise direction. Dawuro shares boundaries with Konta Special Wereda in west, Jimma zone (Oromiya Region) in northwest, Hadiya and Kambata-Tambaro zones in northeast, Wolayta zone in east and Gamo-Gofa zone in southeast. Dawuro has an area of $4,436 \mathrm{~km}$ square it has five Woredas, and one Town administration namely Essara, Tocha, Maraka, Genabosa, Loma and Tarcha Town Administration. The landscape of Dawuro is mostly mountains, plateaus, deep gorges and low land plains. Some of the mountains are Essara, Shasho, Sharo, Gugi, Gazo, Gumati, Hayo, Athso saddle mountains, Hathsinga and Gulo. The plateau cover areas extend from Gora upland in Loma Wereda to the border of Konta Special Wereda in east-west direction and from Waka town to the confluence of Zigna, Mansa and Omo rivers in northsouth direction of Essara and Tocha Woreda. The altitude of Dawuro ranges, from 500 meter around the confluence of Mansa and Omo rivers in special area Bona-balala of Adabacho kebele in Essara Woreda to 3,000 meters above sea level (a.s.l.) at Tuta in Tocha Wereda. Thus, Dawuro exhibits climatic variations from lowland to highland.

Dawuro enriched with a variety of trees and plant species and natural vegetation/forest. For instance, ChabaraChurichura National Park, natural forests along Gojeb and Omo rivers valleys and other bigger rivers in the zone such as Mansa, Zigna and Gelo revisers in Essara and Tocha Woreda contain a large number of natural vegetation that is important for bio diversity farther investigations. Dawuro also endowed with 
perennial rivers whose springs are the highlands aforementioned. Some of the bigger rivers include Buk'a, Shata, Wuni and Zayiri in Mareka Woreda, Wogayi, Zigna, Dibisa, Yarda, Chawa, Shepa in Tocha Woreda Zo'a, Kotoro, Panta, Koma, in Genabosa Woreda, Karethsa hatsa, Mawula, in Loma Woreda, and Mansa, Dalta, Gelo, Sumbursa, Dema, Chawa, Solantya, Banja, and Chofere small lake in Bubayilga, which is found in research conducting Woredas of the zone. All these rivers and others of Dawuro are tributaries of Gojeb and Omo rivers. Dawuro people belong to Omotic family. The language of Dawuro people is Dawurotsuwa (in Latin orthography). Since 2016, Dawurotsuwa has been serving as a medium of instruction in school from grade1 through 10 grades as a subject and oral communication in the Zone's different government offices. In 2014, the population of Dawuro nationality estimated to be 600,121 according to annual statistical abstract of CSA and reported by BoFED of SNNPRS and its population density is 135.28 people per square kilometer. While, Dawuro were been not well known by most Ethiopian and western scholars until now while, the nation endowed in its remarkable history and fascinating culture and their heritage. Among the heritages, two amazing ones are the king Dawuro (kawo Hlala) Great defensive Walls and the longest woodwind musical instrument in the world locally called "Dinka" (4 to 5 meters long, and four in number) are the main one.

Dawuro had been a highly centralized powerful independent Kingdom, until Emperor Menelik incorporated it into Modern Ethiopia in 1891. The area under cultivation estimated to be 100,395 ha of the total 446, 082 ha area of the Zone according to the zonal agricultural department unpublished data. The dominant crops growing around the study area are Enset (Enset ventricosum) maize (Zea mays) coffee (Coffea arebica) wheat (Triticum aestivma) barley (Hordeum vulgare), pea (Pisum sativum), bean (Phaseous vugaris), potato (Solanum tuberosum), Tomato (Lycopersicum esculentum L.), onion (Allium cepa L.) and different fruits and root and tuber crops as well as spices and herbs according to Dawuro zone agricultural department socioeconomic data and own survey interview and practical observation in research conducting zone.

In Dawuro zone Enset plant is produced in all of the Woreda while its production potential varies based on the topography and size of land holding level of producer farmers. Except the mentioned points, all production, processing, postharvest management system, topography and culture of Dawuro people are almost all similar throughout the zone. The similarity of people in all activities leads to conclude that the research conducting Woredas results and outcome can represent other woredas in the zone. While the resource potential and utilization varies from Woreda to Woreda due to different reasons. This research focused on Essara Maraka and Tocha Woreda, which is representative of the remaining woredas in the zone, because it covers the large share of Enset plant production processing and marketing area in the zone.

\section{Mareka Tocha and Essara woreda}

Maraka, Tocha and Essara woreda are located $17 \mathrm{~km}, 37$ $\mathrm{km}$ and $79 \mathrm{~km}$ from Dawuro zone capital Tarcha town. Both three woreda has three agro-ecology named as Dag (high altitude), Woynadega (middle altitude) and kola (low altitude). In all woreda Enset processors are women and girls.

\section{Methods of data collection}

The data was collected by conducting survey on three Woredas of Dawuro zone (Marka, Tocha and Essara) and during the survey period 200 female processers were contacted to obtain appropriate information about Enset plant pesiduo stem, and corm processing and marketing techniques, 13 locally 'bulla and kocho' collectors, 21 local trades, 6 local wholesalers were selected randomly and interviewed out of 24,38 and 13 local collectors, traders and wholesalers respectively. Informal survey was commenced, the three woreda agriculture and natural resource office horticultural crop experts, randomly selected 2 individual Enset processer women at household level from each kebele. Formal survey was commenced by purposive sample selection of 150 $(43.33 \%, 36.67 \%$ and $26.67 \%$ from Tocha, Mareka and Essara woreda) Enset processer woman from male headed, $51(40 \%, 36 \%$ and $24 \%)$ women from female headed household selecting from 24 kebeles $(22.43 \%)$ out of the 107 kebele in the three Woreda. potential Enset producer male households head in three woreda 72,955 and femal headed household are 12,321. Out of this, Enset processer 150 women from male headed and 101 from female headed household were selected with purposive sampling method. The research questionnaire was pre-tested using a pilot survey in 2 kebele before the actual work started under the supervision of the researcher for two days. Then necessary modification were made and the field survey conducted by the enumerators under the supervision and practical survey performing of the researcher Secondary data was 
collected from different sources such as annual reports of the responsible woreda and zone, books and magazines of different scholars.

\section{Sampling methods}

\section{Sample determination}

To find sample size of the respondent women the criteria, used for specifying a sample size appropriate sample size, the level of precision (sampling error is \pm 5 ) and confidence is $95 \%$ confidence level that is, 95 out of 100 samples will have the true population value within the range of precision specified.

Therefore in current research the sampling technique is used Yamane, (1967:886) provides a simplified formula to calculate sample sizes. The formula used to calculate the sample sizes is A 95\% confidence level and $\mathrm{P}=$ 0.05 assumed. Then the formula used is

$\mathrm{n}=\frac{N}{1+N(e) 2}$

Where $\mathrm{n}$ is the sample size, $\mathrm{N}$ is the population size of Enset processer women and $e$ is the level of precision. When this formula applied to the above sample of Tocha Maraka and Essara, woreda purposively selected 450 Enset processer women we get:

$\mathrm{n}=\frac{N}{1+N(e) 2}=\frac{405}{1+405(0.05) 2}=201$

Therefore, in the current research, 150 household Enset processers from male headed and 51 from female headed house hold selected and interviewed from 24 kebele of three woreda to identify the role of women pseudo stem and corm processing level of the area.

\section{Method of data analysis}

Qualitative and Quantitative descriptions by using frequency and percentage were employed to describe women role in Enset processing and marketing along the chain. Descriptive statistics was used to explain that the socio demographic characteristics of the women actors, mean, standard deviation and percent etc. in the channel. Market concentration was calculated by $\mathrm{C} 4$ (the first four markets) the regression analysis takes place OLS (leaner regression) by using STATA and SPSS software version 12 and 20 respectively.

\section{Gender analytical tool was used}

In current research the three-step framework form of Gender Analysis such as Questions about roles and activities of gender (WHO DOES WHAT? or What do men and women do, and how and where do they do it?, questions about access and control WHO HAS WHAT? (Who has access to and control of knowledge, resources, services and decision-making?) and questions about the influencing factors WHY? (What is the social, political and/or economic situation that explains the answers to the above questions? and what are the cross-cutting issues? Between male and female in Enset processing women and girls analyzed in detail.

\section{Model specification for analysis}

Linear regression analysis was used in current research to assess the association between one dependent variable with more than two continuous independent variables.

The independent variable used in the current research was women role in Enset processing. The processed amount of kocho and bulla by women in house hold level was consumed and partially sold. The objective women to process it, was to fulfill the demand gap of household edible food item and to generate income as one of main source for women. The independent variables are more than tow and the appropriate model is liner the linear regression equation for analysis used was that:

$y i=\beta o+\beta 1 X 1+\epsilon 1$

$y i=$ is the dependent variable that is the role of women in Enset pseudo stem processing to obtain 'kocho, bulla and fiber' processed by male and female headed house hold women. $x i=$ is the independent variables. The coefficient $\boldsymbol{\beta}$ is the intercept while, $\beta 1$ is the slop coefficient that is $y i$ changes by ${ }^{\beta 1}$ units for every unit change in $x i$

$$
\begin{aligned}
\frac{d y_{i}}{d x_{i}} & =\beta_{1} \\
y_{i} & =\beta_{0}+\beta_{1} x_{i 1}+\beta_{2} x_{i 2}+\ldots \beta_{n} x_{i n+} \varepsilon_{i}
\end{aligned}
$$

Where $(i=1,2,3 \ldots 17)$

$\mathrm{yi}=$ the role of women to process 'kocho, bulla and fiber' from pseudo stem and corm of Enset plant in the area 
xi1 $=$ is the Enset size processed pseudo stem processed by women

$\mathrm{xi} 2 \mathrm{is}$ Processed kocho by women and obtained from a single Enset plant

$\mathrm{xi} 3=\mathrm{is}$ amount of processed bulla by women in $\mathrm{kg}$

xi4 $=$ Processed Fiver by Women from Single Enset Plant Obtained

xi5 = Female number of Enset processer women household (Fmale): is the family size of Enset processer women male head household

xi6 $=$ is the more actors in processing Enset plant become edible

xi7 = is chopping Enset to processes kocho, bulla and fiber

xi8 $=$ is the amount of kocho and bulla supplied to market to sell per household

\section{Definition of variables}

The independent variable was used in current research was the role of women in Enset processing and supplying marketable surplus at household level and marketed per household in $\mathrm{kg}$. The independent variable defines as:-

\section{Dependent variables}

\section{Enset size (ES)}

It is continuous dependent variable and measured by $\mathrm{kg}$. It was hypostasized to know the processed Enset pseudo stem processed by women

\section{Processed kocho by women (PKW)}

It was continuous dependent variable measured by $\mathrm{kg}$ and it was hypothesized to know how much kg kocho a single Enset plant has been processed by women and obtained and to measure the quantity of kocho, is amount of processed bulla by women in $\mathrm{kg}$

\section{Processed Bulla by Women (PBW)}

It was continuous dependent variable measured by $\mathrm{kg}$ and it was hypothesized to measure the volume of bulla processed by women from a single Enset plant
Processed fiber by women from single enset plant obtained (PFW)

It was continuous dependent variable and measured by $\mathrm{kg}$ and it was hypothesized to know the volume of fiber obtained from a single Enset plant

\section{Female family size of enset processer household head (Female)}

It was continuous dependent variable and measured by number female family member in households. It was hypothesized to know the positive link of female family size. As number of female family members increases the enset pseudo stem and corm processing is simple and otherwise the reverse is true. Dereje Fekadu (2009), labour was an essential farm input that influences every farm activity. The labour that was available in the household can be categorised into children and adult labour. On average $46.7 \%, 47 \%$ and $63.6 \%$ of the labour was that of children, where the rest being adult labour, in the lowlands, mid-altitude and highland areas of Enset producers respectively.

More actors in processing enset plant become edible (proc)

It is dummy variable measured by participant's level and it takes one for female participants and zero for male participants in Enset processing.

\section{Chopping enset to processes kocho, bulla and fiber (Chop)}

It is dummy variable measured by taking value one for female processers and zero for male processers in Enset pseudo stem chopping.

Kocho and bulla supplied to the market to sell per household (market)

It is continuous variable measured by $\mathrm{kg}$ and hypostasized to know the positive link of kocho bulla and fiber supplied to the market per household processers with obtained income of women.

\section{Results and Discussion}

This chapter presents gender role especially women and girls in Enset pesudo stem and corm processing to become edible food item the role female in area was to high and the participation male in Enset processing too 
low or almost none. Therefore, the findings from the descriptive, statistics and econometric model analysis of the current study were discussed in this chapter.

\section{The role of women in enset processing value and marketing chain}

\section{Enset size}

The survey data analysis in current research in table 2 inducts that Enset plant can supply sufficient food from single plant and for its all processing activities the role of women and girls were very crucial because within very few days female can convert big enset pseudo stem and corm to edible food item and they can sustain their food demand and even they can supply surplus produce for market sufficiently. While, the amount of kocho bulla and fiber processed from a single plant is significantly affected by the size of Enset plant at 1\% level and it indicates that the big size plant can supply much pseudo stem than small size and the processed kocho, bulla and fiber from a single big size much more than that of small sized one. The amount of kocho, bulla and fiber obtained varies from plant to plant and from area to area (high, medium and low altitude) respectively. In the some way $93.7 \%$ and $94.7 \mathrm{of}$ the respondents agreed that $5-10 \mathrm{~kg}$ bulla and $0.25 \mathrm{~kg}$ fiber processed from single plant. The unit difference was directly related to the size of the plan. Based upon the morphology and the type of use, farmers in North Omo tend to put Enset plants into two categories, "male-and "female". Usually all the Enset plants within a particular variety (as classified by farmers) are put into a single "sex" category, i.e. a variety is either male or female Alemu et al., (1991).

\section{Number of Female in Enset processing family}

According to current research, female number increment in family size of Enset processer women determine the amount of kocho, bulla and fiber processing from pseudo stem positively. Enset plant processing needs more labor force and all of the activities depends on family labor in the community; hence the large number size female family can process more pseudo stem than less female family size. As indicated in table 2 female family size $>=$ 5 was processes more kocho, bulla and fiber than blow 3 female family holding family. The econometric data analysis female role in Enset pseudo stem and corm processing was significantly affected by female number exist in the family to participate kocho, bulla and fiber processing at 5\%,1\% and $1 \%$ level. Therefore, the survey results show as the large female family holder household can participate in Enset pseudo stem processing in better performance and they obtain high value of kocho, bulla and fiber. Because the activities performed in Enset pseudo stem like chopping needs sufficient labor and in most rural household female family labor plays significant role.

\section{The role of gender in enset value chain}

The role of women and girls, in Enset processing and marketing chain of Dawuro zone was affected by number of female labor in the family to process pseudo stem of the plant, to be edible kocho, bulla and fiber. Because female labor play significant role in chopping, pseudo stem and corm of enset plant and its work load lay on female group only and male participation was/ is protected by working culture of the community. In addition to this technologically poor instrument application, poor market facility, income own right affects women. Based on these factors, Enset processing, farm management, and marketing main activities embrace on the shoulder of female than male in the community. Vale addition of kocho and bulla through processing significant role player in the community based on survey data analysis are women and girls. In the same way Katie MacEntee et al., (2013), finding the labor divisions is based on culture and tradition and no one is involved in the processing except women." Many participants when asked about men processing Enset laughed at the ridiculousness of the suggestion Therefore, the econometric analysis of the survey data finding of current research concluded that the number of women and girls in the family can affect Enset processing at $1 \%$ significant level that means as indicated in table 4 number of female increased in the family can increase enset processing capacity of women and if not it reduce the processing capacity. Therefore, female number in the family significantly influences Enset processing due to current research finding

\section{Chopping}

Chopping Enset and processing kocho, bulla and fiber from it was significantly affecting the volume of kocho and bulla obtained from single plant at $1 \%$ level. In current research data analysis processing activities or chopping performed by female group and during this time female cut the Enset plant by knife and the outer stem coverage separated by small pieces, then the separated stanch locally known as "kashincha" was obtained from pseudo stem (the scraped leaf sheaths) locally call it "Morgiya, shedeya, geduwa" and 
"godethauncha" which made from the inner or underground stem exasperated corm mixed together with fermented Enset yeast or locally called as "Gama" and finally it results processed kocho. Bulla is also obtained from chopped kashinch through wrapping and the whitecolored starch concentrate is mixed with the very soften yeast of the fermented Enset 'gama' and covered with leaf of Enset and stored in selective place at least 20 days and at most 4 months and above for consumption and marketing purpose. In such value addition activities female plays significant role. The kocho and bulla processing and its value addition by female group from poketha (separating the pseudo steam of Enset into different parts such as 'Morgiya', 'shedeiya' 'giduwa' and 'kashincha' are indicated on value chain map figure 1 blow. Enset processing is carried out by women and girls using traditional tools and the process are laborious, tiresome, and unhygienic.

In kocho bulla and fiber processing value chain the role of female is significant in the chain. As we consider the value chain map of current study above, female change the Enset pseudo stem in to processed kocho, bulla and fiber by using indigenous knowledge they change Enset in to edible kocho and bulla by passing very tedious work load and challenges. In kocho and bulla processing male doesn't participate in the community and it is also culturally taboo for male to participate in kocho and bulla processing. In Dawuro zone there was/is no institution to support female group in kocho and bulla processing technology and capacity building activities. Therefore to add kocho and bulla value in the area work load reduction for female group is very important and it needs intervention by responsible body.

\section{Kocho bulla and fiber marketing}

Women play significant role in Kocho, bulla and fiber marketing because all kocho, bulla and fiber processed by them were supplied to the market only by female. The reason was in kocho, bulla and fiber marketing is female obligation and it was culturally forbidden to male to sale it and even purchase it from the market in the community. According to the current study, marketing behavior of kocho, bulla and fiber depends on female group and it affects the marketing level of kocho, bulla and fiber supplied to market at $1 \%$ level. That means kocho, bulla and fiber marketing activities performed by all in all female group than male and it is taboo for male group to sale the processed kocho, bulla and fiber to the market. The kocho, bulla and fiber marketing system in the area based on gender sensitive issue that is given more attention for female group and they perform sole in marketing activities. The amount of kocho and bulla purchased per household for consumption is depends on the existence of female purchasers and sellers in the market and the consumer's income states in the community. Therefore, the current research finding indicates that kocho bulla and fiber marketing system of the area affected by female participants, while, loading and unloading kocho and bulla, transporting from village to woreda level market by pack animal is difficult for female group and it reduce the amount of kocho and bulla supplied to consumers. Therefore, it may needs awareness creation for male groups in the community and capacity building for female group by organizing structured cooperatives.

Bulla is the permissive food product of Enset extracted from freshly decorticated pseudo stem mass. Bulla extraction is commonly practiced only in high altitude environment because the highland Enset cultivars has big stem as compared to lowland and the volume of bulla extracted from single Enset much more than low land one.

\section{Market channel of Kocho, Bulla and fiber in Dawuro zone}

Kocho bulla and fiber market channel of Dawuro zone in current research is depends on selling and buying activities performed by different participants such as local kocho, bulla and fiber processer women (producers) and supplier to the local village market, local collectors from processers in village market, woreda level traders (Balle, Waka and Tocha markets), whole sellers, Wolaita Sodo town administration consumers, regional, central retailers and consumers. The kocho, bulla and fiber marketing channel of Dawuro zone actors or participants were female and it needs intervention to improve the channel.

The current study finding in the figure 3 indicates that the market channel of the area is/was based on the amount of kocho, bulla and fiber supplied by local processer women and those processer women doesn't decide the market price rather than local collectors and consumers. The local kocho, bulla and fiber market structure and activities performed in the marketing system more participant were female group and they cannot bargain the local collectors and consumers price decision power because they have no opportunity trading system at local level and they may exposed to local traders and consumers price exploitation. 
Table.1 Enset processer women from male and female head household and traders sampled in Dawuro zone selected by Woreda level 2016/17

\begin{tabular}{lllllllll}
\hline \multirow{2}{*}{$\begin{array}{l}\text { Name of } \\
\text { woreda }\end{array}$} & $\begin{array}{l}\text { No } \\
\text { kebele }\end{array}$ & \multicolumn{6}{l}{ Household headed by } & \multicolumn{2}{l}{$\begin{array}{l}\text { Sampled Women } \\
\text { processors }\end{array}$} & \multicolumn{2}{l}{ Sampled Traders } \\
\cline { 3 - 9 } & & $* \mathrm{M}$ & $* * \mathrm{~F}$ & $\mathrm{M} / \mathrm{h}$ & $\mathrm{F} / \mathrm{h}$ & Local c & Local t & Wholesal \\
\hline Tocha & 38 & 23,873 & 4,828 & 65 & 20 & 5 & 8 & 2 \\
Mareka & 39 & 27,538 & 4,384 & 55 & 18 & 5 & 7 & 2 \\
Essara & 30 & 21,544 & 3,109 & 40 & 13 & 3 & 6 & 2 \\
Total & 107 & 72,955 & 12,321 & 150 & 51 & 13 & 21 & 6 \\
\hline
\end{tabular}

Source: Dawuro zone agriculture and natural resource department socio economy data, 2017 and own survey sample data Note: *Male, **female, M/head was women sample selected from male headed households and F/head women sample selected from female headed households and local $c ., t$, and wholesale are local collectors, local traders and wholesalers

Table.2 A single plant produced kocho, bulla and fiber in Kg 2016

\begin{tabular}{llllll}
\hline Variable & Measurement & Frequency & $\%$ & Valid \% & Cumulative \% \\
\hline Kocho & $25-50 \mathrm{~kg}$ & 16 & 5.3 & 5.3 & 5.3 \\
& $60-100 \mathrm{~kg}$ & 42 & 14 & 14. & 19.3 \\
& $120-150 \mathrm{~kg}$ & 242 & 80.71 & 80.7 & 100.0 \\
& Total & 300 & 100.0 & 100.0 & \\
Bulla & $5 \mathrm{~kg}$ & 9 & 3 & 3 & 3 \\
& $5-10 \mathrm{~kg}$ & 281 & 93.7 & 93.7 & 96.7 \\
& $>10 \mathrm{~kg}$ & 10 & 3.3 & 3.3 & 100 \\
& total & 300 & 100 & 100 & \\
Fiber & $0.5 \mathrm{~kg}$ & 16 & 5.3 & 5.3 & 5.3 \\
& $0.25 \mathrm{~kg}$ & 284 & 94.7 & 94.7 & 100 \\
& total & 300 & 100 & 100 & \\
\hline
\end{tabular}

Source: own survey finding, 2017

Table.3 The role of female number on Enset processer women work load reduction 2016

\begin{tabular}{crrrr}
\hline $\begin{array}{l}\text { Number of female in Enset } \\
\text { processing HH }\end{array}$ & Frequency & \multicolumn{1}{c}{ V } & Valid \% & Cumulative \% \\
\hline 2-3 female members & 59 & 29.5 & 29.5 & 29.5 \\
3-5 female members & 71 & 35.5 & 35.5 & 65 \\
$>$ 5 female members & 70 & 35 & 35 & 100.0 \\
Total & 200 & 100 & 100.0 & \\
\hline
\end{tabular}

Source own survey 2017, HH is household of enset processer,

Table.4 Econometric analysis of women \& girl role in Enset value addition 2017

\begin{tabular}{lllllll}
\hline Source & SS & df & MS & Number of obs & $=$ & 200 \\
& & & & F(7, 193) & $=$ & 8.8 \\
Model & 3.51292411 & 7 & .635255487 & Prob $>$ F & $=$ & 0.0000 \\
Residual & 19.4037426 & 193 & .066224377 & R-squared & $=$ & 0.3315 \\
& & & & Adj R-squared & $=$ & 0.1360 \\
Total & 22.9166667 & 200 & .07664437 & Root MSE & $=$ & .14734 \\
\hline
\end{tabular}




\begin{tabular}{lllllll}
\hline Women role & Coef. & Std. Err. & $\mathrm{t}$ & $\mathrm{P}>\mathrm{t}$ & {$[95 \%$ Conf. } & Interval] \\
\hline Enset size & .0008305 & .0310451 & 0.12 & 0.009 & -.0325672 & .2152224 \\
Processed kocho & -.1306212 & .1022317 & 1.56 & 0.052 & .1831331 & .0018902 \\
Processed bulla & -.4344125 & .117566 & -2.60 & 0.000 & -.1654934 & -.2010314 \\
Processed fiber & .0934512 & .341211 & 1.23 & 0.041 & .1372210 & .3001234 \\
Female & -.3054178 & .0245110 & 0.21 & 0,008 & .3110122 &,- 0102225 \\
chopping & .0234011 & .0012130 & 0,13 & 0.018 & -.0221034 & .2012310 \\
Market & .6281301 & .1053031 & 5.96 & 0.000 & .4208837 & .8353765 \\
processing & -.1034116 & .0852751 & -1.21 & 0.226 & -.2712409 & .0644178 \\
cons & 1.43032 & .3100371 & 4.61 & 0.000 & .8201383 & 2.040502 \\
\hline
\end{tabular}

Source: own survey result, 2017

Fig.1 Map of Dawuro zone and the study area, Essara, Tocha and Maraka Woreda

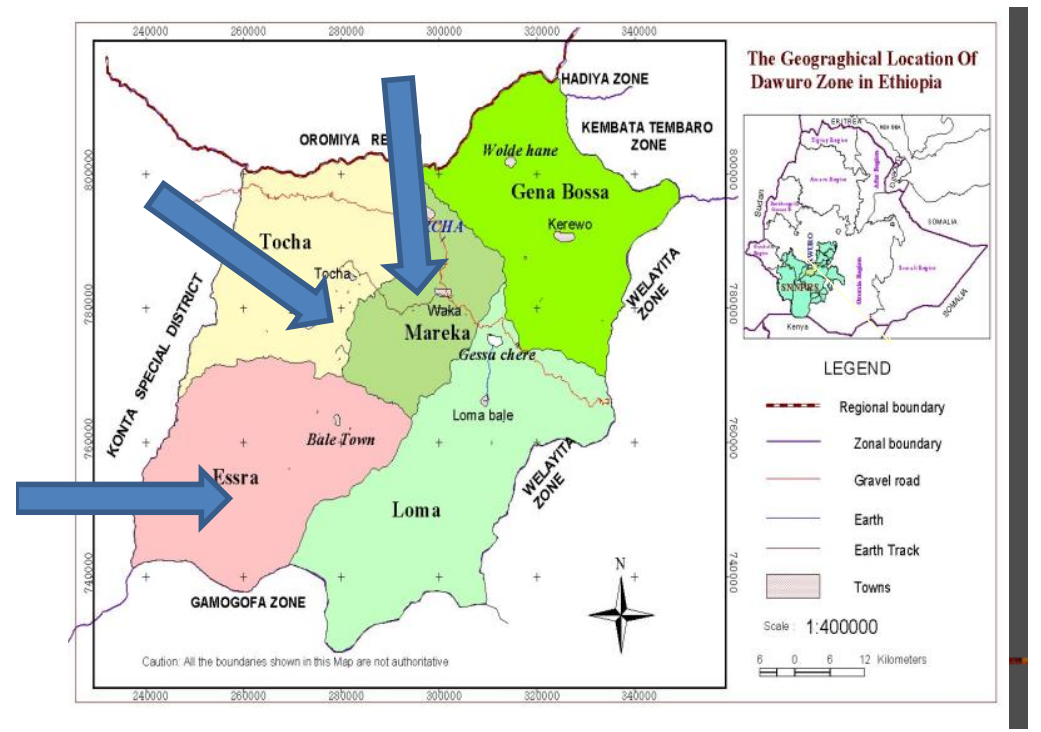

Source: Dawuro Zone planning and finance department

Fig.2 The role of female in Kocho bulla and fiber processing value chain of Dawuro zone 2017

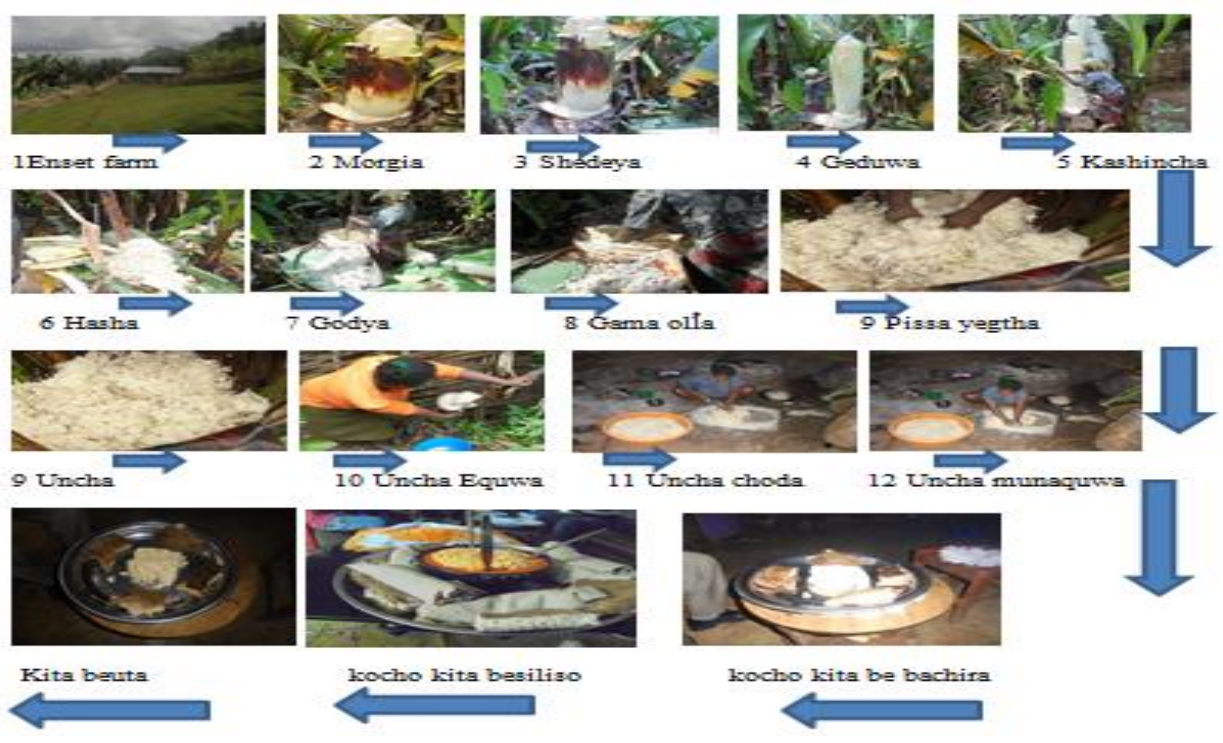

Source: own survey result, 2017 
Fig.3 Kocho, bulla and fiber market channel of Dawuro zone 2017

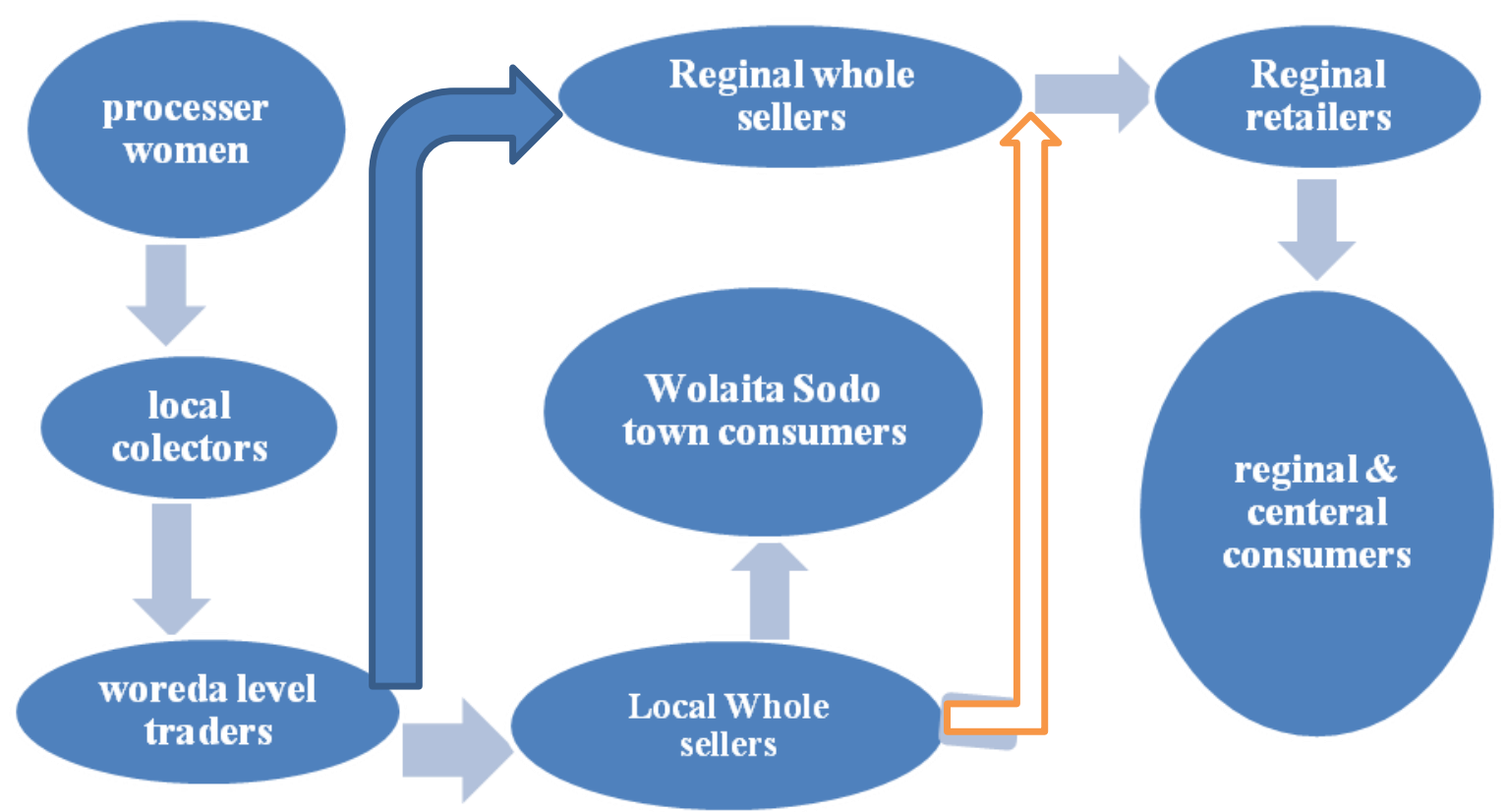

Source: own survey finding, 2017

Female in the community face tedious challenges with related to reproductive and productive activities, poor or almost no technology application in Enset processing and marketing, that hinders their performance in trading capacity and efficiency development unless appropriate intervention mechanism take place.

Local kocho bulla and fiber supplier to village market were female and they add value by processing it and sale to local collectors. Local collectors purchase from village market and they bulk it, grading, packaging in different quantity and selling to woreda level traders. The woreda level traders re bulk the produce and package it, grade it on its quality level, transport to local wholesalers and sell it. The local wholesalers bulk it, grade it and transport to Wolaita Sodo town administration wholesaler's sale it. The Wolaita Sodo wholesalers add value by grading, packaging in different quantity, and selling part of it to Wolaita Sodo retailers and part of it to regional and central wholesalers. Regional retailers distribute the produce for consumers in different quality and quantity level. Final the consumers can purchase the area kocho and bulla from retailers and consume it. Both transaction level fallow different price and pricing system and its price varies from place to place in the channel. Refer figure 3. Enset processing was labor intensive activities it also depends on female then male in community. The more female in family can process more kocho, bulla and fiber than small sized family. In current study finding those family who holds $>=5$ female in the family can process much kocho, bulla and fiber than that of blow 5 female in the family. Therefore, the number of female increment significantly affects the processing kocho, bulla and fiber at household level and marketable surplus. It may recommended that technically improved kocho, bulla and fiber processing equipment supply to women and girls by responsible body is very important because the processing activities was labor intensive and consumes much time of women in the community.

In current research finding Enset processing and marketing main activities hold on the shoulder of female than male in the community. Vale addition of kocho, bulla and fiber through processing significant role player in the community based on survey data analysis were women and girls. The work load such as chopping pseudo stem, kocho, bulla and fiber processing and transporting to marketing area depends on female in the community. While, the role of women and girls affected by working culture of the community and poor technology or local equipment, utilization for Enset processing. It may be highly recommended that female capacity building through technologically improved processing equipment application training and replacing local processing equipment by technologically improved 
instrument and awareness creation intervention by government and any responsible body is important solution to reduce women and girls work load in the area. The kocho, bulla and fiber marketing channel of Dawuro zone actors or participants were female and the culture of the community prevents male participation in enset produce marketing activities therefore, it needs intervention to improve the channel by creating awareness on male group to change the attitude of male with related to working culture of the community.

Female in the community face tedious challenges with related to reproductive and productive activities, poor or almost no technology application in Enset processing and marketing that hinders their performance in trading capacity and efficiency development. Therefore, the responsible body should supply workload reducing technology and instrument supply intervention mechanism through innovating new Enset processing technology, introducing technologically improved processing equipments, disseminating new technology at woreda and kebele level and training awareness creation for females and girls on new equipment utilization by responsible body is recommended.

The university and research centers should conduct research on Enset processing machine development and supplying to Enset processer woman and girls to improve their processing capacity development and to reduce their work load at community level is highly recommended and the regional and local government may support the technology developers in budget and creating conducive working environment for researchers is highly recommended.

\section{Conflicts of Interest}

The author declare there are no conflict of interest regarding to the publication of this paper

\section{References}

Alemu Kefale A. and Sandford S. 1991. Enset in North Omo Region Farmers' Research Project (FRP).

\section{How to cite this article:}

Alemayehu Asfaw Amamo. 2018. The Role of Women in Enset Markt Chain the Cause of Dawuro Zone, Southern Nations Nationalities and Peoples Regional State, Ethiopia. Int.J.Curr.Res.Aca.Rev. 6(4), 36-47

doi: https://doi.org/10.20546/ijcrar.2018.604.006
FARM Africa. Addis Ababa. Ethiopia.

Adugna Gessesse, 2009. Analysis of fruit and vegetable market chains in Alamata, Southern Zone of Tigray: The case of onion, tomato and papaya. M.Sc thesis presented to the school of graduate studies, Haramaya University. pp98.

Asres Ayele, and Omprakash Sahu, 2014. Extension of Enset plant product for rural development in Ethiopia, journal of agricultural economics, extension and rural development vol. 2(3): pp 031040

Dereje Fekadu 2009. Enset and Enset based agroforestry system in densely populated landscapes characterizing farming practices from three regions of Ethiopia on which Enset (Enset ventricosum) is widely profited as a multipurpose crop plant Ethiopian institute of agricultural research (EIAR), Holetta research center Ethiopia.

Tesfaye Abebe 2013. Determinants of crop diversity and composition in Enset-coffee agroforestry home gardens of Southern Ethiopia. Hawassa University, pp. 30.

Demekech Gera 2008. Gender analysis in participatory innovation development: the case of Enset bacterial wilt in Amaro Special Woreda, So uthern Ethiopia Agri-Service Ethiopia

Feleke Woldeyes 2015. Sustainable Enset farming systems for food security and livelihood improvement in Gamo highlands (Arba Minch University)

Katie MacEntee1, Jennifer Thompson1, Sirawdink Fikreyesus2 and Kemeru Jihad3 2013. Enset is a Good Thing": Gender and Enset in Jimma Zone, Ethiopia pp. 106

Steven A. Brandt, Anita Spring, Clifton Hiebsch, J. Terrence McCabe, EndaleTabogie, MulugetaDiro, GizachewWolde-Michael, GebreYntiso, Masayoshi Shigeta, and Shiferaw Tesfaye 1997. Enset-Based Agricultural Systems in Ethiopia. American Association for the Advancement of Science with Awassa Agricultural Research Center Kyoto University Center for African Area Studies and University of Florida pp.23 